\title{
NOTES ON GLOSSINA MORSITANS IN NORTHERN RHODESIA.
}

\author{
By Ll. Lloyd, B.Sc. \\ Entomologist to the Luangwa Sleeping Sickness Commission.
}

\section{Temperature in relation to Glossina morsitans.}

Roubaud has recently recorded (cf. Sleeping Sickn. Bull., III, p. 419) that in West Africa G. morsitans is intolerant of high temperatures, as he has found that specimens exposed to $40^{\circ} \mathrm{C}$. $\left(104^{\circ} \mathrm{F}\right.$.) died within an hour. This species is however adapted to withstand such a temperature in the Luangwa Valley; for during the hot months of October and November the shade thermometer frequently registers from $106^{\circ}$ to $108^{\circ} \mathrm{F}$., seemingly without any ill results to the tsetses.

\section{Duration of the pupal period of G. morsitans.}

Flies which emerged from pupae obtained in October did so after a pupation period of 23 days, on an average. The approximate mean temperature to which these pupae were exposed was $85^{\circ} \mathrm{F}$. The shortest pupation period observed was 21 days, whilst the longest at this temperature was 25 days. Of the apparently healthy pupae obtained during this period $49 \%$ died.

\section{The Dissection of the Salivary Glands of Glossina.}

Workers on the transmission of trypanosomes by various species of Glossina have hitherto been unable to agree as to the part played by the salivary glands in the process. It is of importance therefore that some method of removing the glands be adopted in which the risk of contamination by gut-contents would be reduced to a minimum. The usual method employed hitherto has been to remove the entire viscera by means of pressure on the abdomen, after either the removal of the last segment, or the severance of the abdomen from the thorax. These methods are open to the criticism that the gut, especially if it contains much blood, is liable to rupture; that the glands are liable to lesion; and that it is very difficult to dissect them free from fat body and gut.

The complete salivary glands may be obtained without risk of rupture of the gut by the following method. G. morsitans has been used in the dissections. The fly is held firmly in the hand and a longitudinal incision is made in the median dorsal line of the thorax from the neck to the abdomen. The insect is then immersed in normal salt solution and incisions are made along the transverse groove of the thorax from the median incision almost to the bases of the legs. The strong muscles in the thorax which run in a longitudinal direction should also be severed. A needle is now placed in the anterior end of the longitudinal incision, and another in the posterior end. A gentle longitudinal pull applied to the fly by these needles causes the remainder of the thorax to break across. The alimentary canal breaks between the pharynx and proventriculus, while the salivary glands are drawn out of the abdomen quite free from fat body and with 
only the finer twigs of the tracheal system adhering. It is now a simple matter to dissect away the remainder of the thorax and head till a preparation is obtained consisting of proboscis, pharynx and salivary glands. The figure shows the appearance of such a preparation. The glands when first withdrawn are quite transparent and exhibit an active wriggling motion. They correspond exactly with the salivary glands of $G$. palpalis as described by Minchin." If the pull

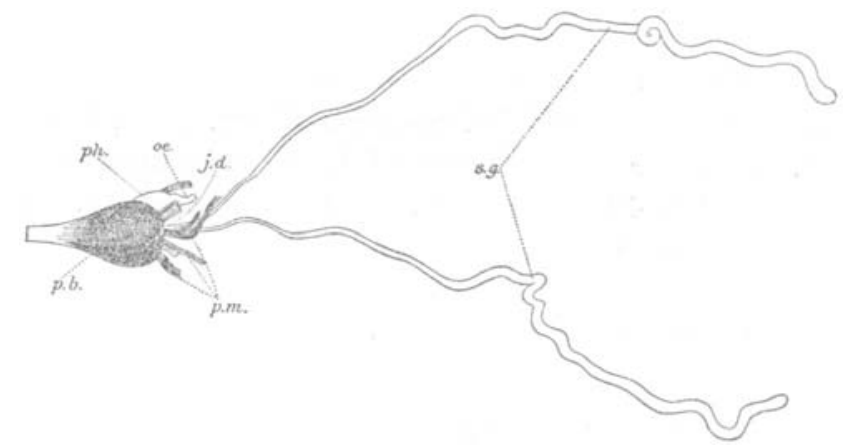

Fig. 1.-Preparation of salivary glands and proboscis of G. morsitans (semi-diagramatic). $\times 10$. $s . g .$, salivary glands ; $j . d$. , junction of salivary ducts ; oe., oesophagus ; ph., pharynx ; $p . b$. , bulb of proboscis ; p.m., muscles of proboscis.

on the fly is not perfectly longitudinal, one of the glands may break off just posterior to the junction of the salivary ducts. Occasionally both the glands break away at this attenuated part of the ducts. In either event the remainder of the thorax attached to the abdomen is dissected off and the protruding glands are withdrawn by means of fine forceps. A little dissection of the anterior end of the abdomen is sometimes necessary to effect this.

Another method that has been adopted with some success is to draw the glands out of the fly by means of the proboscis. A longitudinal median incision is made in the thorax as before and the cut is opened out by means of needles with which the structures in the thorax are loosened. 'The dorsal surface of the head, the eyes and the jowls are then cut through with needles till nothing remains externally connecting the anterior and posterior surfaces of the head, except the thin soft integument immediately behind the proboscis. The proboscis is then seized with forceps and a needle is placed on the last segment of the abdomen. A slow pull on the proboscis causes the glands to be withdrawn as before. This method has been found to fail so frequently however that it cannot be recommended as a working dissection. With several species of Tabanus this latter method of dissecting the salivary glands has been found to be invariably successful.

* E. A. Minchin, Proc. Roy. Soc., Ser. B., Vol. 76 ; Report on the Anatomy of the Tsetse-fly. 